\title{
ERRATUM
}

\section{Philosophy of Systems Biology}

\section{Perspectives from Scientists and Philosophers}

\author{
Sara Green \\ (C) Springer International Publishing AG 2017 \\ S. Green (ed.), Philosophy of Systems Biology, History, Philosophy and Theory \\ of the Life Sciences 20, DOI 10.1007/978-3-319-47000-9
}

DOI 10.1007/978-3-319-47000-9_25

The published version of this book as well as the cover did not include the series volume number. This has now been corrected and the volume number has been updated in the book and cover. 